\title{
DETERMINATION AND COMPARISON OF MINERAL ELEMENTS IN TRADITIONAL CHINESE HERBAL FORMULAE AT DIFFERENT DECOCTION TIMES USED TO IMPROVE KIDNEY FUNCTION - CHEMOMETRIC APPROACH
}

\author{
Archana Kolasani ${ }^{1}$, Hong Xu ${ }^{2}$, Mary Millikan ${ }^{1,3, *}$ \\ ${ }^{1}$ School of Engineering and Science, Victoria University, Australia \\ ${ }^{2}$ School of Biomedical and Health Sciences, Victoria University, Australia \\ ${ }^{3}$ Institute of Sustainability and Innovation, Victoria University, Australia \\ * Corresponding author. Tel.: +61 3 99198278; fax: +61 399198284 \\ Email: mary.millikan@vu.edu.au (Mary Millikan)
}

\begin{abstract}
Traditional Chinese herbal formulae Liu wei di huang (LW) (six-ingredient pill with Rehmannia) and Jin gui shen qi wan (JG) (kidney Qi pill from the golden cabinet) were analysed for $\mathrm{Ca}, \mathrm{Fe}, \mathrm{Mg}, \mathrm{Mn}, \mathrm{Na}, \mathrm{K}$ and $\mathrm{Zn}$ at different decoction intervals by atomic absorption spectroscopy. LW and JG were used to improve the kidney function. JG was higher in all elements than LW. K $\left(1691.29-2372.71 \mathrm{mg} \mathrm{l}^{-1}\right)$ was highest in both formulae LW and JG followed by $\mathrm{Ca}\left(245.31-562.91 \mathrm{mg} \mathrm{l}^{-1}\right)$. Ca, Fe, Mg, Mn and $\mathrm{K}$ were highest at 40 min for LW and Fe, $\mathrm{Mn}, \mathrm{Na}$ and $\mathrm{K}$ were highest at $40 \mathrm{~min}$ for JG. Chemometrics such as principal component analysis, hierarchical cluster analysis and linear discriminate analysis were applied to classify the data and to understand the relation between the elements. Metal intake related to the consumption of decoction has also been studied. Mn made the highest contribution to average daily dietary intakes from the formulae.
\end{abstract}

Key words: Kidney tonifying herbs. Li wei di huang wan, Jin gui shen qi wan, Mineral elements, Atomic absorption spectroscopy

\section{Introduction}

Traditional Chinese medicine (TCM) is one of the oldest healing systems. Clinical diagnosis and Chinese herbology are very important components of TCM. Chinese herbal medicine not only includes plants, but also includes medicinal uses of animals. Most of the principles of TCM were derived from the philosophical basis that contributed to the development of Taoism, and Confucianism (Chen and Xu, 2003, Kaptchuk, 2000). Ancient Chinese scholars noted that all natural phenomena could be categorised into Yin and Yang (two opposite, complementary, interdependent, and exchangeable aspects of nature), everything in the universe consisted of five basic elements (wood, fire, earth, metal, and water), and the universe was constantly changing towards dynamic balance or harmony. Such knowledge was applied to understand, prevent, and cure disease. In TCM, the five Yin (solid) organs are Lungs, Heart, Spleen, Liver and Kidneys and six Yang (hollow) organs are small intestine, large intestine, gall bladder, stomach and San Jiao (called as triple warmer or triple heater). Yin refers largely to the material aspects of the organism and Yang to functions. Disease occurs after a disturbance in YinYang or disharmony in the organs caused by pathogenic (example: anger, joy, sadness, fear) and climatic factors (wind, cold, damp, heat). Treatment aims to expel or suppress the cause and restore balance (Fan, 1996).

The development of herbal formulae has been an empirical process in which the properties of herbs and the effects of combining them have been observed and recorded over many centuries. The resulting classic formulae comprise the basis of treatment in Chinese herbal medicine. The herbs are classified as Yin or Yang and are selected to balance the Yin or Yang of the patient's illness. The qualities of the four energies in the herbs - hot, warm, cold, and cool - are also used to balance the qualities shown in the illness (Yin, 1992). Additionally, the herbs are chosen for their appropriate flavours, with the five flavours - hot, sweet, sour, bitter, and salty matching the five elements - metal, earth, wood, fire, and water - and treating the related organ. The special affinity of a herb and its drying or moistening nature also affect the selection. The simplest way of using the herbs is to make a decoction. This is done by boiling the herbs in a given amount of water to extract their substance (Williams, 1996).

TCM views kidneys as centre of body's Yin or Yang or 'the origin of life' where nutrients are stored and physiological functions takes place. Kidney Yin is the foundation of the Yin fluid (blood, Qi). Kidney Yin moistens and nourishes the organs and tissues of the whole body. Kidney Yang is the foundation of the Yang Qi and is crucial for normal bladder function. Kidney Yang warms and promotes the functions of the organs and tissues. One of the major functions of kidney's Yin - Qi, which is the vital energy of the body, is to promote the transformation of blood. Ancient TCM classics mention that "Kidney Qi excerpts into the bones and transforms into marrow". The liver also plays an important role in the process of transforming Qi into blood because it stores the excess blood that is produced from the marrow. When either the kidneys or liver are not functioning properly, the production of blood will be affected and individuals can acquire a blood-deficiency syndrome (Li and Frierman, 
2006). Traditional Chinese herbal formulae such as Liu wei di huang (LW) is used for kidney and liver Yin deficiency and Jin gui shen qi wan (JG) is used for kidney Yang deficiency.

The medicinal plants traditionally occupied an important position in the sociocultural, spiritual, and ethnopharmacology of rural and tribal lives in different parts of the world. Modern pharmacopeia contains atleast $25 \%$ drugs derived from plants. Approximately $70 \%$ of "synthetic" medicines are derived from plants. The consumption of specific medicinal plants for fighting inflectional diseases and other pathologies falls within a specialist herbivore behaviour. Quality of herbs depends on the presence of active principles. Among those, organic components have deserved most attention. Trace elements in medicinal plants can have a substantial influence on the therapeutic value of herbal remedies: a positive contribution as a source of essential nutrients or even as active principles, or a negative effect because of the accumulation of high concentrations of potentially toxic elements (Prasad, 2008). Medicinal plants can be rich in trace elements (Abou-Arab and Donia, 2000; Basgel and Erdemoglu 2006; Nookabkaew et al., 2006). Despite the relatively small weight proportion of these plant products in the diet, their regular consumption can make a significant contribution to the daily recommended intake (Szentmihályi et al., 2006). It has to be taken into account that only part of the trace elements present in the herbal product is leached into the infusions. Enhanced intake of minerals like $\mathrm{Ca}, \mathrm{K}, \mathrm{Na}$ and $\mathrm{P}$ can be useful in patients with chronic renal failure. Mineral concentrations in herbs used for renal and urinary tract disorders in India have been reported to be higher than in nonmedicinal plants (Rajurkar \& Damame, 1998). The knowledge of the effects and concentrations of bioactive elements in foods and herbs could guide the selection of Chinese herbs in clinical practice in association with TCM theories (Xu and Xu, 2009).

In this study, we have analysed and compared two TCM formulae used to improve the kidney function: Liu wei di huang wan (LW) - formula that nourish and tonify the Yin and Jin gui shen qi wan (JG) - formula that warm and tonify the Yang. LW is known as six-ingredient pill with Rehmannia - formula that nourish and tonify the kidney Yin and used in treating disorders such as dizziness, tinnitus, diabetes, autoimmune diseases, urinary tract infection and sexual inadequacy, etc (Nie and Zhang, 1998, Yang et al., 2006). JG is known as kidney Qi pill from the golden cabinet - formula that warm and tonify the kidney Yang, and that it supports its function of transforming water in particular and used in treating disorders such as interstitial nephritis, arthritis, chronic bronchitis, etc (Bensky and Barolet, 1990). The formulae were analysed for calcium, iron, magnesium, manganese, potassium, sodium and zinc at different decoction intervals by atomic absorption spectroscopy (AAS).

\section{Materials and methods Solutions and reagents}

Standard stock solutions of $\mathrm{Ca}, \mathrm{Fe}, \mathrm{Mg}, \mathrm{Mn}, \mathrm{Na}, \mathrm{K}$ and $\mathrm{Zn}$ at a concentration of $1 \mathrm{gL}^{-1}$ were obtained from Merck, Australia, and working solutions were prepared by dilution of stock solutions in $5 \%(\mathrm{v} / \mathrm{v}) \mathrm{HNO}_{3}(\mathrm{Trace}$ SELECT, 69\%) from Sigma-Aldrich, Australia. Ionization in AAS was controlled by adding a $5 \mathrm{ml}(1 \mathrm{~g} / \mathrm{l} \mathrm{CsCl}+10 \mathrm{~g} / \mathrm{l}$ $\mathrm{La}$, Merck) buffer solution to all samples and standards and made up to final volume of $100 \mathrm{ml}$. Deionized water with a specific sensitivity of $18 \mathrm{M} \Omega$ obtained from Millipore- Milli-Q water purifier system (Milford, USA). All chemicals and reagents were of analytical grade.

Table 1: List of the traditional Chinese herbal formulae

\begin{tabular}{|c|c|c|c|c|}
\hline Formula name & $\begin{array}{l}\text { Chinese } \\
\text { herbs }\end{array}$ & Botanical name & $\begin{array}{l}\text { Plant } \\
\text { part }\end{array}$ & $\begin{array}{l}\text { Amount } \\
\text { (g) }\end{array}$ \\
\hline \multirow[t]{5}{*}{$\begin{array}{l}\text { Li wei di huang } \\
\text { wan }\end{array}$} & $\begin{array}{l}\text { shu di } \\
\text { huang }\end{array}$ & Radix Rehmanniae Glutinosae Conquitae & Root & 24 \\
\hline & shan zhu yu & Fructus Corni Officinalis & Fruit & 12 \\
\hline & shan yao & Radix Dioscoreae Oppositae & Root & 12 \\
\hline & fu ling & Sclerotium Poriae Cocos & Fungus & 9 \\
\hline & mu dan pi & Cortex Moutan Radicis & Root & 9 \\
\hline \multirow{9}{*}{$\begin{array}{l}\text { Jin gui shen qi } \\
\text { wan }\end{array}$} & ze xie & Rhizoma Alismatis Orientalis & Root & 9 \\
\hline & huang & Radix Rehmanniae Glutinosae & Root & 24 \\
\hline & shan zhu yu & Fructus Corni Officinalis & Fruit & 12 \\
\hline & shan yao & $\begin{array}{l}\text { Radix Dioscoreae Oppositae } \\
\text { Radix Lateralis Aconiti Carmichaeli }\end{array}$ & Root & 12 \\
\hline & fu zi & Praeparata & Fruit & 3 \\
\hline & gui zhi & Ramulus Cinnamomi Cassiae & Fruit & 3 \\
\hline & ze xie & Rhizoma Alismatis Orientalis & Root & 9 \\
\hline & fu ling & Sclerotium Poriae Cocos & Fungus & 9 \\
\hline & mu dan pi & Cortex Moutan Radicis & Root & 9 \\
\hline
\end{tabular}




\section{Sample preparation procedure}

The metal content was analysed in two TCM formulae: LW and JG. The herbs involved in the formulae, the amount of each herb used and part of the plant used that were generally prescribed by herbalist are listed in Table 1. The method of preparation of decoction was done according to the Chinese standard procedure. The process of decoction combines the elements of various herbs involved as a means of treating a particular ailment. All the herbs involved in each formula were broken down into small pieces, weighed (Table 1) and kept in a glass beaker with a lid and $200 \mathrm{ml}$ of water was added and allowed to soak for $20 \mathrm{~min}$. Twelve samples were prepared in the same way and performed in triplicates for each formula over the different time intervals (5 to $60 \mathrm{~min}$ ). The mixture was first heated to boiling and kept lightly boiling at different time intervals $(5,10,15,20,25,30,35,40$, $45,50,55$ and $60 \mathrm{~min}$ ). The decoction was allowed to cool to room temperature and then filtered with an ashless filter paper and transferred into $100 \mathrm{ml}$ volumetric flask.

\section{Instrumentation}

The determination of $\mathrm{Ca}, \mathrm{Fe}, \mathrm{Mg}, \mathrm{Mn}, \mathrm{Na}, \mathrm{K}$ and $\mathrm{Zn}$ was done on a Varian spectroAA-400 atomic absorption spectrophotometer (Varian Inc., Mulgrave, Australia) under optimized measurement conditions using hollow cathode lamps. The operating conditions for working concentrations of elements were set as recommended by the manufacturer, given in Table 2.

\section{Data analysis}

The statistical data analysis was made using the SPSS for windows PASW SPSS 18 (Release 18.0.0,

Jul 30, 2009) and Microsoft Excel 2007 with add-in XL-STAT 2010. To obtain more reliable information about the element content relationship, Pearson correlation analysis technique was used. To identify the elemental patterns in the data set, principal component analysis (PCA) was used. In order to classify the data, hierarchical cluster analysis (HCA) - unsupervised pattern recognition technique and linear discriminant analysis (LDA) - supervised pattern recognition technique were used.

Table 2: The operating parameters for working elements

\begin{tabular}{cccc}
\hline Elements & $\begin{array}{c}\text { Wavelength } \\
(\mathbf{n m})\end{array}$ & $\begin{array}{c}\text { Lamp current } \\
(\mathbf{m A})\end{array}$ & $\begin{array}{c}\text { Slit } \\
(\mathbf{n m})\end{array}$ \\
\hline $\mathrm{Ca}$ & 422.7 & 10 & 0.5 \\
$\mathrm{Fe}$ & 248.3 & 5 & 0.2 \\
$\mathrm{Mg}$ & 285.2 & 4 & 0.5 \\
$\mathrm{Mn}$ & 279.5 & 5 & 0.2 \\
$\mathrm{~K}$ & 404.4 & 5 & 0.5 \\
$\mathrm{Na}$ & 330.3 & 5 & 0.5 \\
$\mathrm{Zn}$ & 213.9 & 5 & 1 \\
\hline
\end{tabular}

Table 3: Correlation matrix of elements (Pearson correlation)

\begin{tabular}{llllllll}
\hline Variables & $\mathrm{Ca}$ & $\mathrm{Fe}$ & $\mathrm{Mg}$ & $\mathrm{Mn}$ & $\mathrm{Na}$ & $\mathrm{K}$ & $\mathrm{Zn}$ \\
\hline $\mathrm{Ca}$ & 1 & & & & & & \\
$\mathrm{Fe}$ & 0.531 & 1 & & & & & \\
$\mathrm{Mg}$ & 0.664 & 0.763 & 1 & & & & \\
$\mathrm{Mn}$ & 0.683 & 0.857 & 0.872 & 1 & & & \\
$\mathrm{Na}$ & 0.768 & 0.707 & 0.828 & 0.738 & 1 & & \\
$\mathrm{~K}$ & 0.667 & 0.849 & 0.937 & 0.922 & 0.770 & 1 & \\
$\mathrm{Zn}$ & 0.558 & 0.355 & 0.268 & 0.253 & 0.241 & 0.295 & 1 \\
\hline
\end{tabular}

\section{Results and Discussion \\ Metal content in formulae}

According to the Chinese standard procedure of making decoctions, most formulas are cooked for 20-30 $\min$. The formulas that contain rich, cloying substances should be cooked for 45-60 min. The metal contents of the two formulae LW and JG at different decoction times with 5 min interval from 5-60 min were plotted in Figure 1. The content of essential elements in plants is conditional, the content being influenced by the geochemical characteristics of the soil and by the ability of plants to selectively accumulate some of these elements 
(Miroslawski et al., 1995, Wierzchowska-Renke et al., 1997). Ca, Fe, Mg, Mn, Na, K and Zn were higher in formula JG than LW. Independent sample t-test was done to determine the significant differences between the mean values of the elements in the formulae. The results showed that, except for $\mathrm{Zn}\left(0.91-1.04 \mathrm{mg} \mathrm{I}^{-1}\right)$, significant differences $(p<0.05)$ exist between LW and JG for Ca $\left(245.31-562.91 \mathrm{mg} \mathrm{I}^{-1}\right)$, Fe $\left(10.85-16.92 \mathrm{mg} \mathrm{I}^{-}\right.$ $\left.{ }_{1}^{1}\right), \mathrm{Mg}\left(95.34-147.03 \mathrm{mg} \mathrm{l}^{-1}\right), \mathrm{Mn}\left(3.33-5.16 \mathrm{mg} \mathrm{l}^{-1}\right), \mathrm{Na}\left(40.98-85.54 \mathrm{mg} \mathrm{l}^{-1}\right)$ and $\mathrm{K}\left(1691.29-2372.71 \mathrm{mg} \mathrm{l}^{-}\right.$ $\left.{ }^{1}\right)$. $\mathrm{K}$ was highest in both formulae $\mathrm{LW}$ and JG followed by $\mathrm{Ca}$.

Table 4: $\mathrm{ADDI}^{\mathrm{a}}$ for metals and average metal content by cup of formula

\begin{tabular}{llll} 
Metals & ADDI $\left(\mathrm{mg} \mathrm{d}^{-1}\right)^{\mathrm{a}}$ & Liu wei di huang wan $\left(\mathrm{mg} \mathrm{cup}^{-1}\right)^{\mathrm{b}}$ & Jin gui shen qi wan $\left(\mathrm{mg} \mathrm{cup}^{-1}\right)^{\mathrm{b}}$ \\
$\mathrm{Ca}$ & $1000(800-1200)$ & $24.53(2.45)$ & $56.29(5.62)$ \\
$\mathrm{Fe}$ & $15(10-18)$ & $1.08(7.2)$ & $1.69(11.2)$ \\
$\mathrm{Mg}$ & $350(300-400)$ & $9.53(2.72)$ & $14.7(4.2)$ \\
$\mathrm{Mn}$ & $4(2-5)$ & $0.33(8.25)$ & $0.5(12.5)$ \\
$\mathrm{Na}$ & $2200(1100-3300)$ & $4.09(0.18)$ & $8.5(0.38)$ \\
$\mathrm{K}$ & $3800(1900-5600)$ & $169.12(4.45)$ & $237.2(6.24)$ \\
$\mathrm{Zn}$ & 15 & $0.09(0.6)$ & $0.103(0.68)$ \\
\hline
\end{tabular}

${ }^{a} \mathrm{ADD}$ Is of metals, mean value and range in parenthesis [17]

${ }^{b}$ In parenthesis, \% of ADDI from a cup (100ml) of formulae

Correlation is a measure of association between two variables. The correlation matrix of the elements was presented in Table 3. It can be seen that good correlation exists between all the elements. In order to assimilate the elemental patterns that are meaningful, PCA was performed. The principal components (PC) with Eigen values greater than one were extracted and subjected to Varimax rotation. The results after Varimax rotation: first and second factor were presented in Fig 2. The percentages of variances after the Varimax rotation for the first two components were $64.4 \%$ and $21.6 \%$ respectively. Fig 2 (A) shows the bigger loadings for PC1: $\mathrm{Ca}, \mathrm{Fe}, \mathrm{Mg}, \mathrm{Mn}, \mathrm{Na}$ and $\mathrm{K}$ and PC2: $\mathrm{Ca}$ and $\mathrm{Zn}$. The scores of the two principal components for each formula at different decoction times were shown in Fig 2 (B). From the scores of the PC1, it could be interpreted that $\mathrm{Ca}, \mathrm{Fe}$, $\mathrm{Mg}, \mathrm{Mn}, \mathrm{Na}$ and $\mathrm{K}$ were high in formula JG in the following order: 40, 45, 25, 60, 55 and 30 min. The PC2 score showed that $\mathrm{Ca}$ and $\mathrm{Zn}$ were high in formula JG in the following order: 25, 20, and 35 min followed by formula LW at $10 \mathrm{~min}$. When the loadings and scores in Fig. $2(A)$ and $(B)$ were interpreted, $\mathrm{Ca}$ and Fe were highest in formula JG at $25 \mathrm{~min}$ and 40 min respectively. Zn was highest in formula LW at $10 \mathrm{~min}$.
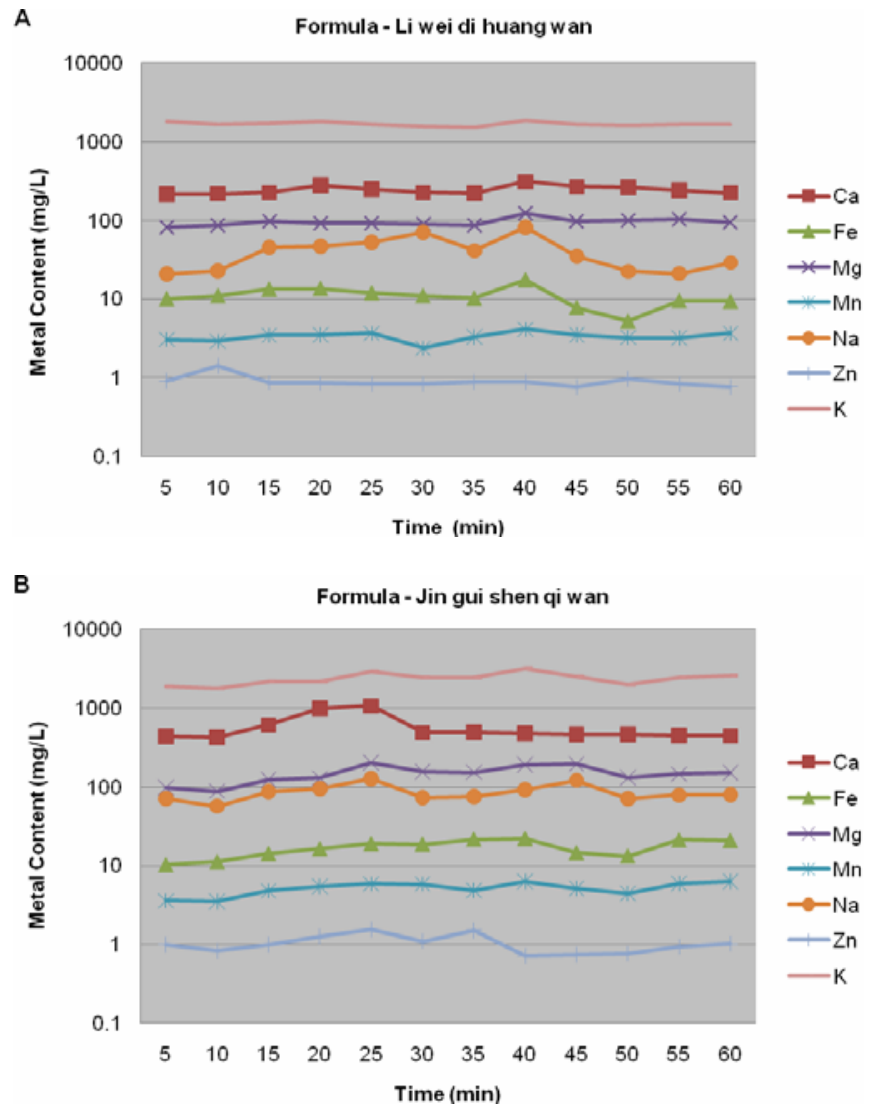

Figure 1: Metal content $\left(\mathrm{mg} \mathrm{l}^{-1}\right)$ of the analysed formulae 

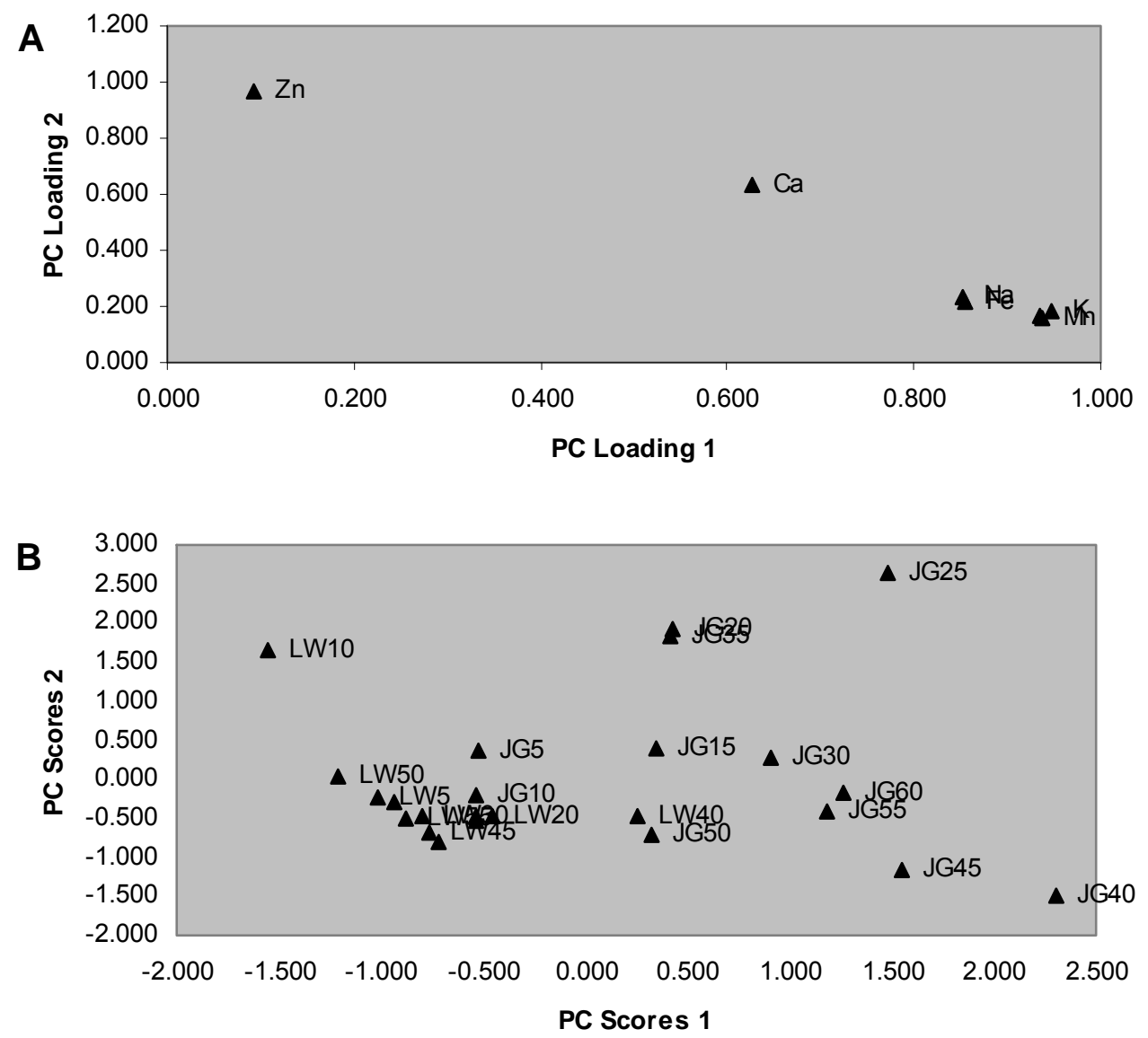

Figure 2: Varimax rotated principal component loadings $(A)$ and scores (B), PC1 versus PC2

HCA was applied to the systematized elemental concentrations and a pictorial description of formulae LW and JG was obtained using Ward's method as an amalgamation rule and the squared Euclidean distance as a measure of the closeness between samples (Fig. 3). The resulting dendrogram gave five concise clusters. The first cluster involved formula LW at 10, 15, 25, 30, 35, 45, 50 and $55 \mathrm{~min}$, as the amount of $\mathrm{Ca}, \mathrm{Fe}, \mathrm{Mg}, \mathrm{Mn}, \mathrm{Na}$ and $\mathrm{K}$ were low in formula LW when compared to JG. The second cluster involved LW at 5,20 and 40 min and JG at 5, 10 and 50 min as all elements except Zn in LW and except Fe in JG followed the same pattern at those given intervals. In addition, $\mathrm{Ca}, \mathrm{Fe}, \mathrm{Mg}, \mathrm{Mn}$ and $\mathrm{K}$ were highest at $40 \mathrm{~min}$ in LW. For JG, comparing the metals at 5 and $10 \mathrm{~min}, \mathrm{Ca}, \mathrm{Mg}, \mathrm{Mn}, \mathrm{Na}, \mathrm{K}$ and $\mathrm{Zn}$ were higher at $5 \mathrm{~min}$ than at $10 \mathrm{~min}$. The metals leached more at $5 \mathrm{~min}$ than at $10 \mathrm{~min}$ for the formula JG. The third cluster involved JG at 25 and $40 \mathrm{~min}$. This is because in JG, Ca, Mg and $\mathrm{Zn}$ were highest at $25 \mathrm{~min}$ and $\mathrm{Fe}, \mathrm{Mn}, \mathrm{Na}$ and $\mathrm{K}$ were highest at $40 \mathrm{~min}$. Fourth cluster involved JG at 30 , $35,45,55$ and 60 min because all the elements except $\mathrm{Zn}$ were higher in JG compared to LW. Fifth cluster involved JG at 15 and 20 min as it followed the same pattern of rise in all elements from 15 to 20 min.

The variation of the metal contents with different decoction times is due to the combination of various herbs in the formula. The herbs in combination contributed to the synergistic effect that varies the percolation of the metals with time. Özcan analysed the mineral contents of Turkish herbal tea at different infusion periods $(3,5$, 7, 9 and $11 \mathrm{~min}$ ). He showed that the mineral contents at different time intervals are not consistent and varied widely depending on the infusion periods (Özcan, 2005). Considering the nutritional properties, he proposed the first period of infusion may be taken as the optimum time for the Turkish herbal tea. One of the primary advantages of decoction is that it is rapidly absorbed by the body; its effects are strong and immediately perceived by the patient. It is not, however, without drawbacks: decoctions are relatively expensive, time consuming and also difficult to prepare. The elemental concentration of the herbal formulas LW and JG at different time intervals obtained in this study provides scientific evidence. This study can further assist Chinese health practitioners to determine the effectiveness of percolation of these metals with time that aids in the prescription of these decoctions to improve kidney function.

Fisher's LDA analysis was performed using the leave-one-out method for model establishment and prediction. The discriminate function revealed a significant association between the formulae and predictors, accounting for $69.05 \%$ of between group variability. The cross validated function showed that overall $91.7 \%$ of original grouped cases correctly classified. 


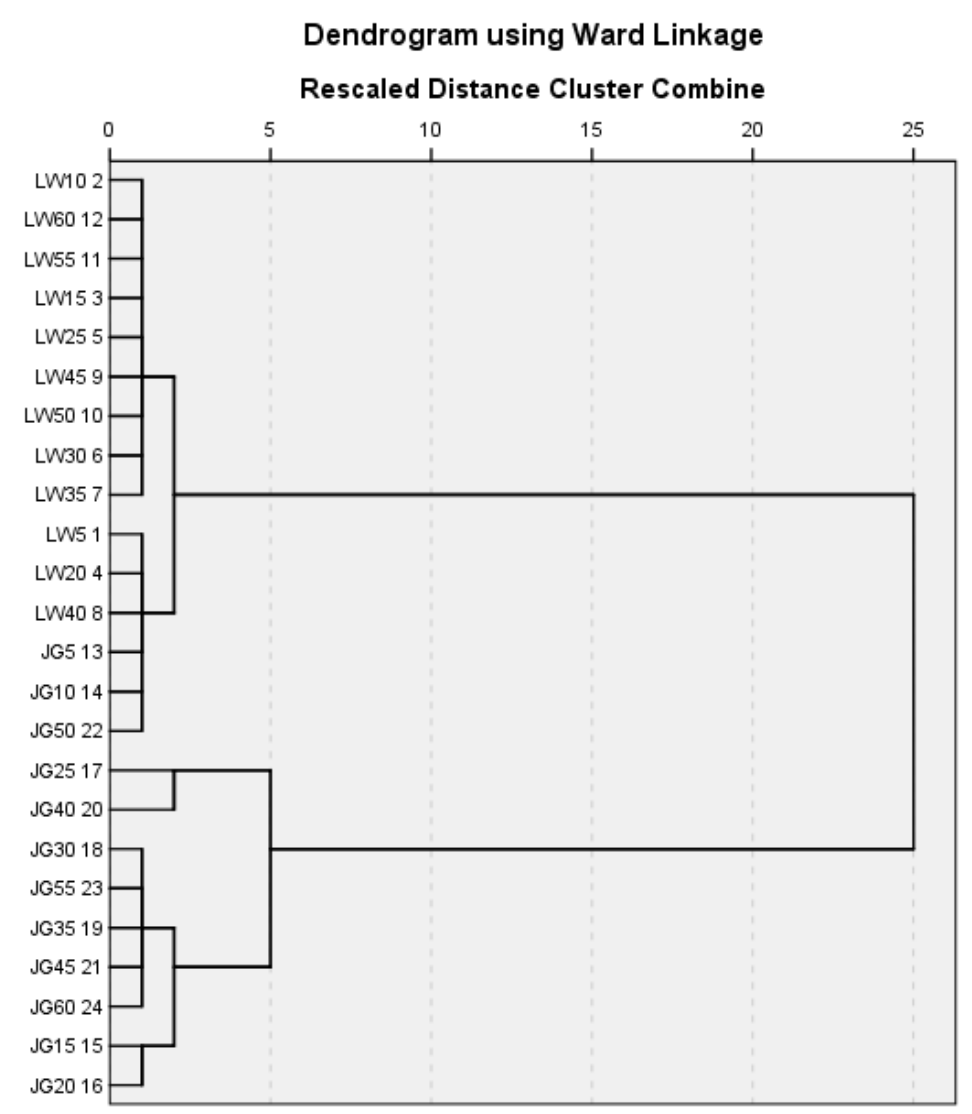

Figure 3: Dendrogram of hierarchical cluster analysis for the formulae LW and JG

\section{Metal intake from decoction of LW and JG}

The two TCM formulae were examined for the contribution of each element on the average daily dietary intake (ADDIs). Table 4 shows the results of the element concentration by cup ( $\mathrm{mg} / 100 \mathrm{ml}$ formula). The percentage contribution of elements to ADDIs was shown in brackets (Table 4). It can be noticed that high contribution to ADDIs in the case of manganese is in agreement with the literature (Fernandez et al., 2002). The next highest contribution to ADDIs was Fe followed by K in both the formulas LW and JG respectively. In chronic renal disease there is a decrease of manganese and iron levels in the kidney (Bogden \& Klevay, 2000). Manganese deficiency can have impact on major physiological processes. Excessive sweating and chronic liver disorders are also causes of manganese deficiency. In TCM's view, as the formula LW and JG are used to treat kidney and liver Yin deficiency (blood-deficiency) and kidney Yang deficiency (urinary difficulty), it can be considered from the elemental concentration approach that the highest contribution of ADDIs of the formulae to $\mathrm{Mn}$ and $\mathrm{Fe}$ might be one of the reasons for using these formulae to improve kidney function.

\section{Conclusions}

The concentration of mineral elements in TCM formulae LW and JG were determined at different decoction times by AAS. Formula JG contains higher amount of $\mathrm{Ca}, \mathrm{Fe}, \mathrm{Mg}, \mathrm{Mn}, \mathrm{Na}, \mathrm{K}$ and $\mathrm{Zn}$ than formula LW. Information of element content in the decoctions of TCM is important to assess their beneficial effects for human health. The data was subjected to chemometrics in order to highlight the possible correlations between the elements and to recognize the patterns with the purpose of identifying the possible influences of soil and climate. Good correlation exists between the analysed elements. PCA showed that Ca and Fe were highest in JG at 25 min and 40 min respectively and $\mathrm{Zn}$ was highest in LW at $10 \mathrm{~min}$. HCA gave significant clusters that highlights 25 min and $40 \mathrm{~min}$ for JG as $\mathrm{Ca}, \mathrm{Mg}$ and $\mathrm{Zn}$ were highest at $25 \mathrm{~min}$ and $\mathrm{Fe}, \mathrm{Mn}, \mathrm{Na}$ and $\mathrm{K}$ were highest at 40 min. Fisher's LDA analyses gave that $91.7 \%$ of original grouped cases correctly classified. The percentage contribution of metals from the decoction of LW and JG gave that Mn had highest contribution to ADDIs.

\section{References}

1. Chen, K.J. and $\mathrm{Xu}, \mathrm{H}$. (2003). The integration of traditional Chinese medicine and Western medicine. European Rev. 11: 225-235. 
2. Kaptchuk, T.J. (2000).The web that has no weaver: understanding Chinese medicine. Illinois,MI. Contemporary Books. pp.1-2.

3. Fan, W. (1996).A manual of Chinese herbal medicine: principles and practice for easy reference. Boston: Shambhala Publications Inc. pp. 7-16.

4. Yin, H. (1992).Fundamentals of Traditional Chinese Medicine. CBT China Book Trading. pp. 10-15.

5. Williams, T. (1996). The complete illustrated guide to Chinese medicine: a comprehensive system for health and fitness. Australia. Element. pp. 174-175.

6. Li, W. and Frierman, D. (2006).Diseases of the kidney \& bladder : diagnosis \& treatment with Chinese medicine. Boulder, CO. Blue Poppy Press. pp. 322.

7. Prasad, M.N.V. (2008).Trace Elements as Contaminants and Nutrients: Consequences in Ecosystems and Human Health. Wiley. pp. $108-137$.

8. Abou-Arab, A.A.K. and Donia, M.A.A. (2000). Heavy metals in Egyptian spices and medicinal plants and the effect of processing on their levels. J. Agric. Food Chem. 48 (6): 2300-2304.

9. Basgel, S. and Erdemoglu, S.B. (2006). Determination of mineral and trace elements in some medicinal herbs and their infusions consumed in Turkey. Sci Total Environ. 359 (1-3): 82-89.

10. Nookabkaew, S., Rangkadilok, N. and Satayavivad, J. (2006). Determination of trace elements in herbal tea products and their infusions consumed in Thailand. J. Agric. Food Chem. 54 (18): 6939-6944.

11. Szentmihályi, K., Hajdú, M., Fodor, J., Kótai, L., Blázovics, A., Somogyi, A. and Then, M. (2006). In vitro study of elements in herbal remedies. Biol Trace Elem Res 114 (1): 143-150.

12. Rajurkar, N.S. and Damame, M.M. (1998). Mineral content of medicinal plants used in the treatment of diseases resulting from urinary tract disorders. Appl Radiat Isot 49 (7): 773-776.

13. $\mathrm{Xu}, \mathrm{H}$. and $\mathrm{Xu}, \mathrm{H} . \mathrm{E}$. (2009). Analysis of trace elements in chinese therapeutic foods and herbs. Am J Chin Med. 37 (4): 625 - 638.

14. Nie, W. and Zhang, Y. (1998). Advances in modern pharmacological study of Liuwei Dihuang prescription. J. Herb. Pharmacol. Chin. J. Herb. Parmacol. Ther. 14 41-44.

15. Yang, S., Zhou, W., Zhang, Y., Yan, C. and Zhao, Y. (2006). Effects of Liuwei Dihuang decoction on ion channels and synaptic transmission in cultured hippocampal neuron of rat. J Ethnopharmacol 106 (2): 166-172.

16. Bensky, D. and Barolet, R. (1990). Chinese herbal medicine:Formulas and strategies. Seattle, Wash. Eastland Press. pp. 275.

17. Miroslawski, J., Wiechula, D., Kwapulinski, J., Rochel, R., Loska, K. and Ciba, J. (1995). The occurence of $\mathrm{Pb}, \mathrm{Cd}, \mathrm{Cu}, \mathrm{Mn}, \mathrm{Ni}, \mathrm{Co}$ and $\mathrm{Cr}$ in selected species of medicinal plants in Poland. Bromat Chem Toksykol. 28 363-368.

18. Wierzchowska-Renke, K., Ivancheva, S. and Kurteva, M. (1997). Effect of environment pollution on the composition of polyphenols and bioelements content in Achillea millefolium L. and Tanacetum vulgare L. Herba Pol. 43 413-418.

19. Özcan, M. (2005). Determination of mineral contents of Turkish herbal tea (Salvia aucheri var. canescens) at different infusion periods. Journal of medicinal food. 8 (1): 110-112.

20. Fernandez, P., Pablos, F., Martin, M. and Gonzalez, A. (2002). Multi-element analysis of tea beverages by inductively coupled plasma atomic emission spectrometry. Food Chem. 76 (4): 483-489.

21. Bogden, J.D. and Klevay, L.M. (2000).Clinical nutrition of the essential trace elements and minerals: the guide for health professionals. Humana Pr Inc. pp. 277. 